\title{
PERAN MASYARAKAT DESA SEJAHTERA DALAM PENGELOLAAN WISATA HUTAN MANGROVE DI KECAMATAN SUKADANA KABUPATEN KAYONG UTARA
}

(The Role Of Sejahtera Village Community In Managing Mangrove Forest Tourism In Sukaana Subdistrict Kayong Utara Regency)

\author{
Wahyuti, Iskandar, Gusti Hardiansyah \\ Fakultas Kehutanan Universitas Tanjungpura Jalan Daya Nasional Pontianak 78124 \\ Email: wahyutikayong.@gmail.com
}

\begin{abstract}
The community role is needed in the implementation of mangrove forest tourism management, especially in planning activities. The role of the community is the involvement of community itself in the development activities, both in the planning, implementation, evaluation, and the stages of esnjoying the results of the development itself. The purpose in this descriptive qualitative study was to determine the role of community in managing mangrove forest tourism in the subdistrict of Sukadana of Kayong Utara regency. Data collection techniques consist of observation, interviews, and documentation. While the analysis was carried out with descriptive analysis technique. The results of this study indicate that the role of of the sejahtera village community in managing mangrove forest tourism is limited to the maintenance of natural resources, maintenance of cleanliness and nursery of mangrove forests. Due to mangrove forest management is still fully managed by The Gunung Palung National Park Agency, the role of the community in the management of tourism in mangrove forests is still low. Therefore, the involvement of the surrounding community needs special attention and other related parties in utilizing mangrove forest tourism.
\end{abstract}

Keyword: community role, mangrove forest, themanagement of mangrove tourism

\section{PENDAHULUAN}

Ekowisata merupakan konsep pariwisata yang menitik beratkan pada pesona alam yang indah dan menariks siapapun yang mengunjunginya, dimana ada kekayaan alam harmoni lingkungan dan tentu saja keberlangsungan didalamnya (Rosid 2012). Namun, pada hakekatnya pengertian ekowisata adalah suatu bentuk wisata yang bertanggungjawab terhadap kelestarian area yang masih alami (natural area), memberi manfaat secara ekonomi dan mempertahankan keutuhan budaya bagi masyarakat setempat. Pengelolaan wisata akan dapat berjalan dengan baik di setiap desa, apabila bertujuan mendukung pembangunan kepariwisataan yang berkelanjutan dengan berasaskan kepada prinsip ekowisata yaitu menyelaraskan antara pengelolaan lingkungan, ekosistem dan pembangunan ekowisata (firmansyah 2003).

Peran masyarakat adalah keterlibatan masyarakat itu sendiri dalam kegiatan pembangunan, baik dalam tahap perencanaan, pelaksanaan, 
evaluasi, sampai pada tahap menikmati hasil pembangunan itu sendiri. Menurut (Puspasari 2000) peran masyarakat dalam menunjang keberhasilan pembangunan timbul sebagai akibat pergeseran tumpuan pembangunan.

Masyarakat mempunyai hak dalam menikmati kualitas lingkungan hidup yang dihasilkan hutan, dan juga dapat mengetahui rencana peruntukan hutan, pemanfaatan hasil hutan, dan informasi kehutanan. Selain haknya tersebut, masyarakat berkewajiban untuk ikut serta memelihara dan menjaga kawasan kawasan hutan dari gangguan perusakan dan pemerintah wajib mendorong berbagai kegiatan dibidang kehutanan. Peran masyarakat merupakan proses dimana masyarakat turut serta mengambil bagian dalam pengambilan keputusan tentang proyek, program dan kebijakan (Hadi 1999).

Wisata hutan mangrove merupakan wisata alam yang terletak di desa sejahtera kecamatan sukadana kabupaten kayong utara dengan luas wilayah $141,14 \mathrm{Km}^{2}$ yang memiliki potensi sumberdaya alam yang masih asri dan memiliki pemandangan wisata yang menarik untuk dikunjungi. Wisata hutan mangrove dapat dikembangkan sebagai tempat rekreasi terbuka dengan lokasi yang strategis dan memerikan kemudahan maupun kenyamanan bagi Alat-alat yang digunakan dalam pengambilan data antara lain: alat tulis, kamera, kuisioner, dan perekam suara. Jenis penelitian ini merupakan penelitian kualilatif yaitu mendeskripsiksan peran masyarakat pengunjungan saat melakukan rekreasidi kawasan tersebut. Wisata hutan mangrove sering kali dikunjungi oleh masyarakat sekitar daerah, maupun masyarakat luar daerah. Peran masyarakat merupakan keterlibatan masyarakat merupakan keterlibatan itu sendiri dalam pembangunan, baik dalam tahap perencanaan, pelaksanaan, evaluasi dan sampai pada tahap menikmati hasil. Penelitian ini bertujuan untuk mendeskripsikan peran masyarakat desa sejahtera dalam pengelolaan wisata hutan mangrove Di Desa Sejahtera Kecamatan Sukadana Kabupaten Kayong Utara.

\section{METODE PENELITIAN}

Penelitian ini dilakukan di Desa Sejahtera Kecamatan Sukadana Kaupaten Kayong Utara dan dilaksanakan selama 1 minggu efektif di lapangan mulai tanggal 25 juni sampai 1 juli 2018. Dengan jumlah kepala keluarga $536 \mathrm{KK}$, dengan sampel 26 orang masyarakat dan 4 orang informan kunci yakni Kepala Desa, Kepala RT, Resort Tanjung Gunung, Dan Dinas Pariwisata. Kriteria masyarakat yang akan dijadikan responden yaitu; a). masyarakat berada di sekitar kawasan taman wisata hutan mangrove terutama desa sejahtera. b). berdomisili menetap minimal 5 tahun. c). sehat jasmani dan rohani.

desa sejahtera dalam pengelolaan wisata hutan mangrove Di Desa Sejahtera Kecamatan Sukadana Kabupaten Kayong Utara. Penelitian ini dilakukan menggunakan metode survey dengan teknik melakukan wawancara 
mendalam dengan informan yang telah dipilih. Teknik pengumpulan data dilakukan dengan cara observasi, wawancara dan dokumentasi. Teknik analisis data menggunakan analisis deskriptif. Metode yang digunakan adalah metode deskriptif kualitatif. Adapun subyek penelitian sebagai sumber data primer adalah masyarakat Desa Sejahtera, yaitu masyarakat, Kepala Desa, Kepala RT, Dinas Pariwisata, Resort Tanjung Gunung (BTNGP). Teknik pengumpulan data melalui wawancara, observasi langsung, dan dokumentasi dengan alat berupa pedoman wawancara, alat tulis, perekam dan kamera. Data yang berasal dari naskah, wawancara, observasi, dokumen, dan sebagainya, kemudian dideskripsikan sehingga dapat memberikan kejelasan terhadap kenyataan atau realitas tentang pengelolaan wisata hutan mangrove

HASIL DAN PEMBAHASAN Karakteristik Responden Berdasarkan Peran

Tabel 1. Frekuensi Responden Berdasarkan Peran (Frekuensi respondents based on role)

\begin{tabular}{clcc}
\hline No & \multicolumn{1}{c}{ Peran } & Frekuensi & Persentase (\%) \\
\hline 1 & Menjaga sumberdaya alam & 14 & 50 \\
2 & Menjaga kebersihan & 13 & 43,33 \\
3 & Pembibitan mangrove & 2 & 6,66 \\
\hline \multicolumn{2}{c}{ Total } & 30 & 100 \\
\hline
\end{tabular}

Karaktristik responden berdasarkan peran dalam penelitian ini dikelompokkan menjadi tiga kategori yaitu menjaga sumberdaya alam, menjaga kebersihan, pembibitan mangrove. Berdasarkan olahan primer hasil pengamatan lapangan diperoleh kategori menjaga sumber daya alam sebanyak $50 \%$, menjaga kebersihan 43,33\%, dan pembibitan 6,66 \%.

Peran masyarakat dalam pengelolaan wisata mangrove merupakan tindakan seseorang untuk terlibat dalam suatu kegiatan baik secara langsung maupun tidak langsung guna tercapainya tujuan yang diinginkan seperti dalam pengelolaan hutan. Menurut (Hadi 2005) peran atau partisipasi masyarakat merupakan proses dimana masyarakat turut serta mengambil bagian dalam keputusan, tanpa adanya peran masyarakat sangat sulit untuk mewujudkan tujuan penglolaan, bahwa masyarakat bisa memahami atau mengerti berbagai permasalahan yang muncul serta memahami keputusan akhir yang akan diambil.

Berdasarkan hasil wawancara, dengan masyarakat mereka mengatakan selama ini yang lebih berkompeten dalam mengelola kawasan wisata hutan mangrove yaitu masyarakat setempat dan Balai Taman Nasional Gunung Palung, karena status kawasan wisata hutan mangrove masih dimiliki oleh masyarakat yang tinggal di sekitar kawasan. Mereka juga mengatakan adapun peran yang dilakukan oleh masyarakat sekitar kawasan hanya sebatas menjaga sumber daya alam, menjaga kebersihan, dan pesmbibitan mangrove. Menurut (Nazarudin 2010), hal ini karena masyarakat sekitar cenderung memiliki 
peran positif mengenai pengelolaan wisata hutan mangrove, namun tidak hanya di pandang sebagai kawasan wisata alam tetapi penglolaan yang dilakukan juga bermanfaat untuk menjaga wisata hutan mangrove yang ada di kawasan tersebut.

Berdasarkan pasal 69 dan 70 undangundang No.41 tahun 1999 tentang kehutanan, disebutkan bahwa masyarakat berkewajiban ikut serta dalam menjaga hutan dari gangguan perusakan, berperan aktif dalam rehabilitasi, turut berperan serta dalam pembangunan kehutanan dan pemerintah wajib mendorong peran serta masyarakat yang terkait langsung berbagai upaya dalam rangka menyelamatkan dan memanfaatkan hutan, sehingga tetap lestari serta berkesinambungan. Keinginan untuk mewujudkan peran masyarakat dalam pengelolaan wisata hutan mangrove sangat perlu dukungan dari berbagai pihak baik secara material, mental maupun emosional yang terlibat dalam melaksanakan tanggung jawab seseorang untuk kehidupan bersama maupun tujuan yang ingin dicapai. Harapan masyarakat sekitar dalam pengelolaan wisata hutan mangrove setidaknya ada peran swasta dan kebijakan pemerintah supaya turut serta dalam kegiatan pengelolaan, perencanaan, pelaksanaan, evaluasi sampai pada tahap menikmat

Hasil pembangunan tersebut.

Dari hasil wawancara dengan kepala RT, yang mereka inginkan dan mereka harapkan supaya masyarakat yang ada di desa sejahtera khususnya dusun tanjung gunung dapat mengembangkan objekobjek yang ada di Sukadana, seperti pantai pulau datok, pantai pasir mayang, dan air , ini menjadi salah satu destinasi yang banyak diminati oleh wisatawan baik lokal maupun mancanegara. Masyarakat sekitar juga menginginkan dari keterlibatan pengunjung dalam menjaga suasana ketertiban, kebersihan dan kenyamanan dalam memasuki kawasan wisata hutan mangrove. Selain itu masyarakat yang tinggal sekitar kawasan juga berharap supaya wisatawan yang berkunjung ke suatu tempat dengan pelatihan yang baik dan profesional dalam dalam memberikan pelayanan bagi setiap wisatawan sehingga kepuasan wisatawan yang berkunjung selalu di prioritaskan. Namun, masyarakat yang tinggal di sekitar kawasan harus memiliki keyakinan bahwa dalam pengelolaan wisata alam mampu meningkatkan kesejahteraan hidup mereka dan pada akhirnya juga dapat meningkatkan pendapatan daerah (PAD) yang ada di kabupaten kayong utara.

Berdasarkan dari hasil wawancara dengan kepala bidang pariwisata Kabupaten Kayong Utara menerangkan bahwa adapun sarana dan prasarana yang sudah dibangun dikawasan wisata hutan mangrove yaitu jembatan. Sarana dan prasarana tersebut merupakan penunjang bagi masyarakat setempat maupun wisatawan yang berkunjung supaya mendapatkan kemudahan serta kenyamanan untuk memasuki kawasan wisata hutan mangrove. Meskipun dengan sarana dan prasarana yang serba berkekurangan untuk dinikmati oleh wisatawan, namun tidak menjadi alasan bagi mereka untuk berkunjung ke wisata hutan mangrove. 
Menurut (Tarigan 2005), perencanaan pengelolaan dapat berarti mengetahui dan menganalisis kondisi saat ini, meramalkan perkembangan beragai faktor yang tidak dapat dikontrol dan yang relevan, memperkirakan dapat tercapai, serta mencapai langkah-langkah tujuan tersebut. Di tahun 2016 sepenuhnya didasarkan pada berbagai permasalahan masyarakat seperti dalam pengelolaan wisata hutan mangrove yang saat ini belum memiliki sarana dan prasarana yang belum mencukupi. Peran masyarakat dalam pengelolaan wisata hutan mangrove selama ini masih tergolong rendah, sehingga keterlibatan masyarakat sekitar perlu mendapat perhatian khusus dari pihak-pihak terkait dalam memanfaatkan wisata hutan mangrove. Sebagaimana dalam penelitiannya (Sadono 2013) peran masyarakat sekitar kawasan hutan mangrove dapat berjalan dengan baik apabila masyarakat sekitar wisata hutan mangrove dapat mengetahui informasi rencana kegiatan pengelolaan, menyatakan pendapat atau saran mengenai kebijakan pengelolaan, dilibatkan dalam pelaksanaan dan pengawasan kegiatan pengelolaan sehingga semua masyarakat sekitar kawasan wisata hutan mangrove mendapatkan manfaat dari kegiatan pengelolaan kawasan tersebut.

\section{Kesimpulan}

Peran masyarakat dalam pengelolaan wisata hutan mangrove secara umum masih dikelola oleh Balai Taman Nasional Gunung Palung, karena status kawasan tersebut masih dalam perlindungan Balai Taman Nasional Gunung Palung. adapun bentuk bentuk peran masyarakat dalam pengelolaan yang dilakukan yaitu sebatas menjaga sumber daya alam,menjaga kebersihan lingkungan dan pembibitan.

\section{Saran}

1. Diharapkan semua pihak atau instansi terkait dapat bekerjasama membantu peran masyarakat desa sejahtera dalam pengelolaan wisata hutan mangrove supaya berperan aktif dan memberikan masukan sehingga pengelolaannya yang selektif dan terintegrasi seperti mengadakan penyuluhan, penanaman bibit mangrove.

2. Di perlukan peningkatan aksesibilitas sarana dan prasarana penunjang sehingga pengembangan wisata hutan mangrove, terutama fasilitas-fasilitas yang tidak ada di dalam kawasan wisata hutan mangrove, seperti tempat sampah, tempat parkir, kursi, dan plang.

\section{DAFTAR PUSTAKA}

Aryanto. 2003. Eviromental Marketing Pada Ekowisata Pesisir Menggerakkan Rakyat Daerah Otonom. Jakarta

Firmansyah dan yoswati. 2012. Pembangunan Ekowisata Di Kecamatan Tanjung Balai Asahan, Sumatera Utara: Factor Ekologis Hutan Mangrove. IV(2 ):346-359

Hadi, Sudharto P. 2005. Bahan Kuliah Metodologi Penelitian Sosial, Kuantitatif, Kualitatif, Dan Kaji Tindak. Program Studi Megister Ilmu Lingkungan, UNDIP

Giri, et all. 2011. Status and distribution of mangrove forest of the world using earth observation satelite data. Global Ecology and Biogeography, 20(1), 154-159. 
JURNAL HUTAN LESTARI (2019)

Vol. 7 (1) : 160 - 165

Harahap. N. 2006. Penilaian Ekonomi Ekosistem Mangrove Dan Aplikasinya Dalam Perencanaan Wilayah Pesisir. Yogyakarta. Graha ilmu

Ilyas, Lumangkum A, Natalina H. 2015. Peran Serta Masyarakat Dalam Pelestarian Hutan Mangrove Di Desa Batu Gajah Kabupaten Natuna. Jurnal Hutan Lestari
Rosid. 2012. Menggali Potensi Ekowisata Sungai Ciliwung Bersama Bird Group. Ciliwung

Safei M. 2005. Kajian Partisipasi Masyarakat Dalam Pelestarian Hutan Mangrove. (Studi Kasus Di Desa Moroboro Kecamatan Bone Dan Desa Labulu-Bulu Kecamatan Parigi Kabupaten Muna Provinsi Sulawesi Utara). (Tesis). Bogor. Institut Pertanian Bogor. 